\title{
Recombinant Factor VIIa plus Surgery for Intracerebral Hemorrhage
}

\author{
Christina S. Sutherland, Michael D. Hill, Anthony M. Kaufmann, \\ Joseph A. Silvaggio, Andrew M. Demchuk, Garnette R. Sutherland
}

\begin{abstract}
Background: Hyperacute surgical evacuation of intracerebral hemorrhage is associated with a high rebleeding rate. The peri-operative administration of rFVIIa to patients with intracerebral hemorrhage may decrease the frequency of post-operative hemorrhage, and improve outcome. Methods: Patients receiving recombinant activated factor VII (rFVIIA) therapy immediately prior to acute surgery were collected at two centres. The intracerebral hemorrhage (ICH) score and ICH Grading Scale were determined, as was long-term outcome using the modified Rankin Scale. Residual/ recurrent clot was evaluated by comparing pre-operative to postoperative CT scans. Results: Fifteen patients with intracerebral hemorrhage received 40-90 $\mu \mathrm{g} / \mathrm{kg}$ of rFVIIa and underwent surgical hematoma evacuation at a median time of five hours following symptom onset. Median pre-operative clot volume was 60 ml, decreasing to $2 \mathrm{ml}$ post-operatively. There were no thromboembolic adverse events. Thirteen patients survived, 11 (73\%) were independent, and two (13\%) had a moderate to severe disability. These outcomes were significantly better than expected based on the median ICH score (40\% mortality) and based on median ICH Grading Scale (18\% good outcome). Conclusions: The pre or perioperative administration of rFVIIa resulted in minimal residual or recurrent hematoma volume and may be an important adjunct to surgery in patients with intracerebral hemorrhage.
\end{abstract}

RÉSUMÉ: Facteur VIIa recombinant associé à la chirurgie dans l'hémorragie intracérébrale. Contexte : L'évacuation chirurgicale hyperaiguë de l'hémorragie intracérébrale est associée à un taux élevé de resaignement. L'administration de rFVIIa periopératoire chez les patients présentant une hémorragie intracérébrale pourrait diminuer la fréquence des hémorragies postopératoires et améliorer l'issue. Méthodes : Les patients ayant reçu du rFVIIa immédiatement avant la chirurgie ont été identifiés dans deux centres. Les scores du ICH et du ICH Grading Scale ont été déterminés de même que l'issue à long terme au moyen du Modified Rankin Scale. Le caillot résiduel ou récurrent a été évalué en comparant les CT scans préopératoires et postopératoires. Résultats : Quinze patients ayant présenté une hémorragie intracérébrale ont reçu de 40 à $90 \mu \mathrm{g} / \mathrm{kg}$ de rFVIIa et ont subi une évacuation chirurgicale de l'hématome 5 heures (temps médian) après le début des symptômes. Le volume médian du caillot avant la chirurgie était de 60 ml et de $2 \mathrm{ml}$ après la chirurgie. Aucun incident thromboembolique n'a été observé. Treize patients ont survécu dont 11 (73\%) étaient indépendants et 2 (13\%) avaient une invalidité de modérée à sévère. Ces résultats étaient significativement meilleurs qu'anticipés vu le score médian du ICH (40\% de mortalité) et du ICH Grading Scale (18\% de bons résultats). Conclusions : Un hématome résiduel ou récurrent dont le volume était minime a été observé suite à l'administration pré ou périopératoire de rFVIIa. Le rFVIIa peut être un traitement d'appoint important à la chirurgie chez les patients présentant une hémorragie intracérébrale.

Can. J. Neurol. Sci. 2008; 35: 567-572

Spontaneous intracerebral hemorrhage (ICH), accounts for approximately $15 \%$ of strokes. ${ }^{1,2}$ Clinical outcome is poor with a 30 day mortality of approximately $40 \%$, and functional independence achieved by only $20 \%$ at six months. ${ }^{3-5}$ Beyond stroke unit care, aimed at reducing complications of immobility, ${ }^{6-8}$ there are no convincing acute treatments for spontaneous ICH including surgical evacuation and hemostatic therapy. Currently, rationale for surgical intervention for $\mathrm{ICH}$ includes reducing intracranial pressure, ${ }^{9}$ decreasing the potential for inflammation and its associated brain edema, ${ }^{10}$ and improvement of brain perfusion. ${ }^{11}$

The first prospective randomized ICH study comparing surgery to conservative treatment was published over 40 years ago. ${ }^{12}$ This study did not find a benefit for surgery over medical management of ICH. Since then, additional randomized clinical trials, each with its own limitations, have examined the efficacy

From the Calgary Stroke Program, Department of Clinical Neurosciences (CSS, MDH, AMD, GRS), University of Calgary, Calgary, AB; Section of Neurosurgery (AMK, JAS), University of Manitoba, Winnipeg, MB, Canada.

Received December 6, 2007. Final Revisions Submitted May 26, 2008.

Correspondence to: Michael D. Hill, Calgary Stroke Program, Department of Clinical

Neurosciences, University of Calgary, Foothills Hospital, Rm 1162, 1403 29th Street NW, Calgary, Alberta, T2N 2T9, Canada. 
of surgery for $\mathrm{ICH} .{ }^{13-20}$ None of the studies have shown an overall significant benefit for surgery over medical management. ${ }^{21-23}$ Surgery may worsen outcome by virtue of : (1) the elderly population taken to the operating room, (2) the known trauma from surgical manipulation/exploration of brain, and (3) a high rate of rebleeding post-operatively. ${ }^{15,24}$ Substantiating the lack of surgical benefit, the recent international STICH trial of 1033 patients showed no overall benefit of surgery for supratentorial ICH when clot evacuation was performed early, within 24 hours of stroke onset, compared to deferred surgery or medical care only. ${ }^{20} \mathrm{~A}$ secondary analysis showed that surgery may be beneficial for a subset of patients with a Glascow coma scale (GCS) $\geq 9$ and in whom hemorrhage is located within $1 \mathrm{~cm}$ of the cortical surface. Based on this observation, the STICH II trial has begun to determine if early surgery with craniotomy in patients with superficial hematoma is better than medical treatment alone. ${ }^{23}$

Bleeding from a vessel with pathology in the arteriolar wall, either hypertensive or amyloid angiopathy, will preclude the normal contraction of that vessel. ${ }^{25}$ The rate of bleeding from small vessels may be slow enough to allow time for hemostatic intervention and surgery to be beneficial. These same pathological changes, could account for difficulties in achieving hemostasis during surgery and increase the risk for postoperative hemorrhage..$^{15,24}$ The use of a peri-operative hemostatic agent should theoretically decrease bleeding prior to, during and following surgery.

Intracerebral hemorrhage is a dynamic process: hematoma expansion can occur for several hours following onset - this expansion is associated with increased mortality and morbidity. ${ }^{26,27}$ This observation combined with the knowledge that hematoma volume is an important predictor of mortality following $\mathrm{ICH},{ }^{28}$ led to the idea that treatment with a hemostatic agent such as recombinant activated factor VII (rFVIIa) may be beneficial for such patients. The phase IIB trial of the hyperacute medical treatment of ICH within four hours of symptom onset with rFVIIa suggested benefit by reducing hematoma expansion and decreasing poor long term outcomes. ${ }^{29}$ Unfortunately a large phase III trial could not demonstrate efficacy for reducing poor outcomes despite demonstrating reduced hematoma expansion compared to placebo. ${ }^{30}$

Since post-operative hemorrhage may account for the lack of benefit of surgery over medical management alone and recombinant fVIIa is a powerful hemostatic agent, this study examines whether hyperacute surgical evacuation of intracerebral hematoma combined with hemostatic therapy is able to prevent post-operative hematoma reaccumulation, resulting in improved clinical outcomes following $\mathrm{ICH}$.

\section{METHODS}

After publication of the phase IIB trial of rFVIIa for the treatment of ICH, a protocol for compassionate use of rFVIIa for spontaneous ICH within four hours of symptom onset was developed. Eligibility for rFVIIa was determined by presentation within four hours of symptoms or surgery was planned. Eligibility for surgery was defined by symptom progression. Patients presented in one of two ways. Those presenting to neurology received rFVIIa followed by a decision for surgery, while those presenting to surgery the decision was made to proceed to theatre with adjunctive rFVIIa. Drug administration was based upon estimated weight at a dose ranging from 40-90 $\mu \mathrm{g} / \mathrm{kg}$. This dose was based upon the phase IIB study where efficacy was similar among all doses, but side effects were greater at $160 \mu \mathrm{g} / \mathrm{kg}$. Actual dose received was calculated based upon the patients' weight after acute treatment.

Data were collected at two Canadian institutions: Foothills Medical Centre (Calgary, Alberta) and the Health Sciences Centre (Winnipeg, Manitoba). The patients were nonconsecutive ICH patients who presented in the hyperacute phase following ICH, and were eligible for surgical intervention based on clinical judgment, from March 2005 to December 2006. Patients were taken to the operating theatre as quickly as possible. Recombinant activated factor VII was administered in the emergency room or in the operating theatre prior to surgery. Outcomes were collected immediately post-operatively and in clinical follow-up at three-six months. All patients underwent baseline and follow-up CT scans, and pre- and post-operative hemorrhage volumes were calculated using the $\mathrm{ABC} / 2$ method. ${ }^{31}$ In a few cases, post-operative CT scans were repeated in order to assess any changes and improvements. However, only the first post-operative CT scan was used to calculate post-operative clot size. Outcome was assessed from a review of the hospital chart and outpatient clinic records. The individual assessing patient outcome was not involved in acute treatment and inpatient care; the surgeon of record did not contribute to the measurement of outcome. Clot volume was independently determined and reviewed with a neuroradiologist.

Data are reported using simple descriptive statistics, and comparisons were made to expected outcome. All data are presented as median (range). The pre-operative ICH score was calculated for all patients, and the median score was used to determine the expected proportion of deaths, which was compared to the actual number of deaths. The ICH Grading Scale score was also determined, as this score has been shown to better predict 30-day mortality compared to the ICH score. ${ }^{32}$ Using the ICH Grading Scale (ICH-GS), the expected proportion of good outcomes and deaths were also calculated and compared to the actual numbers. A good outcome was defined as a mRS score of $\leq 2$, and a poor outcome was defined by a score $>2$.

\section{RESULTS}

Fifteen patients over a 1.5 year period are reported. The median age was 68 years (25-81 years) and $9(60 \%)$ were male [Table 1]. Four patients $(27 \%)$ were receiving anticoagulation therapy; in such cases, vitamin $\mathrm{K}$ and fresh frozen plasma were also administered concurrently. The median interval from symptom onset to the baseline CT scan was three hours (1.5-12 hours) and the median GCS was 8 (3-14). The median baseline hematoma volume was $60 \mathrm{ml}(15-164 \mathrm{ml})$. Intraventricular extension was observed in six patients with median baseline intraventricular hemorrhage (IVH) volume of $20 \mathrm{ml}(0.5-25 \mathrm{ml})$ [Table 2].

All patients were rapidly transported to the operating theatre, at a median of five hours (3-24 hours) from symptom onset to surgery. In all patients, surgery commenced within one hour of receiving rFVIIa. The patient who received surgery 24 hours following initial symptom onset began deteriorating at another hospital prior to transfer for neurosurgical evaluation and 
Table 1: Baseline patient characteristics

\begin{tabular}{lcc}
\hline Variable & $\begin{array}{c}\text { Median } \\
\text { (Mean } \pm \text { SD) }\end{array}$ & Range \\
Age (years) & 68 & $25-81$ \\
Male \% & $63 \pm 16)$ & - \\
Ethnic group (number) & 60 & \\
$\quad$ Caucasian & $11(73 \%)$ & \\
$\quad$ Asian or Pacific Islander & $2(13 \%)$ & \\
$\quad$ African American & $1(7 \%)$ & \\
$\quad$ Other & $1(7 \%)$ & \\
Systolic Blood Pressure & 160 & $112-290$ \\
& $(172 \pm 49)$ & \\
Diastolic Blood Pressure & 81 & $53-180$ \\
& $(92 \pm 30)$ & \\
Glasgow Coma Score (median, & $8(6-13)$ & $3-14$ \\
interquartile range) & & - \\
Anticoagulation (\%) & 27 & $1-5$ \\
$\begin{array}{l}\text { ICH Score(median, } \\
\text { interquartile range) }\end{array}$ & $2(2-3)$ & \\
$\begin{array}{l}\text { ICH-GS Score (median, } \\
\text { interquartile range) }\end{array}$ & $9(8-11)$ & $7-13$ \\
\hline
\end{tabular}

treatment. The operating time was relatively short, with a median operating time of 113 minutes (54-240 minutes). The patients received $60 \mu \mathrm{g} / \mathrm{kg}(40-92 \mu \mathrm{g} / \mathrm{kg})$ of $\mathrm{rFVIIa}$ in the emergency room $(n=9)$ or operating theatre $(n=6)$ immediately prior to surgery. Craniotomy was performed for the 13 patients with supratentorial hemorrhages, and sub-occipital craniectomy for two patients with cerebellar hemorrhages [Figure 1]. Only one of the patients whose hemorrhage was localized to the cerebellum had an external drain inserted for obstructive hydrocephalus. Hematoma removal and hemostasis was achieved by employing microsurgical technique, as the use of the microscope augments visualization through restricted surgical corridors. Minimal blood loss, and readily achieved hemostasis was observed in all but one patient. That patient received rFVIIa at a dose of 60 $\mu \mathrm{g} / \mathrm{kg}$ immediately prior to surgery. Intraventricular hemorrhage was removed only when the clot extended directly into the ventricular system. In one patient who had received a dosage of rFVIIa of $80 \mu \mathrm{g} / \mathrm{kg}$, it was observed during surgery that the clot was firm and difficult to evacuate. Despite this, a $100 \%$ post-op reduction in hematoma size was achieved.

Post-operative CT scans were conducted 17 hours (3-24 hours) following surgery. Median post-operative residual/ recurrent clot volume was $2 \mathrm{ml}(0-30 \mathrm{ml})$. Post-operative intraventricular extension was seen in four patients with a median estimated post-operative IVH volume of $5 \mathrm{ml}(1-25 \mathrm{ml})$. The median percent reduction in hematoma volume, determined by comparing the pre- and post-op CT imaging studies, was $97 \%$ $(60-100 \%)$. Scans performed after this time did not show additional hematoma, other than a slight increase in hematoma volume in one patient. [Figure 2]

The median ICH score and ICH-GS were 2 (1-5) and 9 (7-13), respectively [Table 1]. All of the patients under 75 years-of-age survived. Two deaths occurred in patients with baseline hemorrhage volumes of $54 \mathrm{ml}$, cerebellar, and $164 \mathrm{ml}$, lobar. The former never regained consciousness after surgery, and the latter died in hospital four months post-op from a bowel obstruction with secondary sepsis [Figure 3]. There were no clinically

Table 2: Hematoma data

\begin{tabular}{|c|c|c|}
\hline & Pre-op & Post-op \\
\hline \multicolumn{3}{|c|}{ Location of Hemorrhage (Right, Left) } \\
\hline Lobar hemisphere & $8 \mathrm{R}, 3 \mathrm{~L}$ & \\
\hline Putamen & $1 \mathrm{R}, 1 \mathrm{~L}$ & \\
\hline Cerebellum & $1 \mathrm{R}, 1 \mathrm{~L}$ & \\
\hline \multicolumn{3}{|l|}{ Volume of ICH } \\
\hline Median (range) & $60(15-164) \mathrm{ml}$ & $4(0-30) \mathrm{ml}$ \\
\hline Mean \pm SD & $68 \pm 45 \mathrm{ml}$ & $6 \pm 9 \mathrm{ml}$ \\
\hline IVH extension (number $(\%)$ ) & $6(40)$ & $4(27)$ \\
\hline Median volume (range) & $20(0.5-25 \mathrm{ml})$ & $5(1-25) \mathrm{ml}$ \\
\hline Mean volume $\pm \mathrm{SD}$ & $15 \pm 10 \mathrm{ml}$ & $9 \pm 9 \mathrm{ml}$ \\
\hline \multicolumn{3}{|l|}{ Edema (number $(\%)$ ) } \\
\hline None & $4(27)$ & $5(33)$ \\
\hline Mild & $7(47)$ & $6(40)$ \\
\hline Moderate & $4(27)$ & $4(27)$ \\
\hline
\end{tabular}

evident adverse arterial or thromboembolic events and no patient suffered a post-operative cerebral infarction. Routine troponin levels and ultrasound studies were not obtained after rFVIIa administration. Of the surviving 13 patients, 11 (73\%) were independent ( $\mathrm{mRS} \leq 2)$, and $2(13 \%)$ were significantly disabled $(\mathrm{mRS}>2)$ at three-six month follow-up [Figure 4]. Of the 11 independent patients, two had made a complete recovery, six patients had only minor symptoms, such as slight personality changes, homonymous hemianopia, or minor expressive dysphasia; and three remaining patients required the use of a cane or walker to ambulate. None of the surviving patients were left bedridden $(\mathrm{mRS}=5)$. 


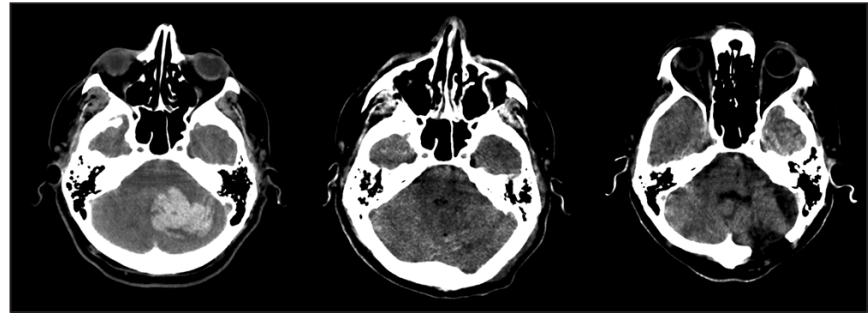

Figure 1: Pre-operative, eight hour and three month post-operative CT images obtained on a 47-year-old man who presented with sudden loss of consciousness. The pre-operative scan (left) demonstrated a cerebellar/brainstem hemorrhage with a calculated volume of $49 \mathrm{ml}$. The post-operative scan (middle) and three month follow-up study (right) showed no evidence of residual clot.

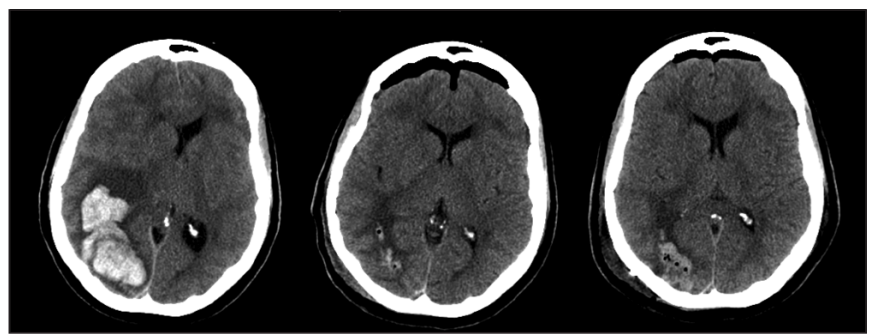

Figure 2: A 75-year-old right handed woman presented to the emergency department with acute headache, left hemiplegia, and left homonymous hemianopia. While being examined in the emergency room, her level of consciousness deteriorated from a GCS of 14 to 7 . The pre-op image (left) shows a large, $78 \mathrm{ml}$, irregularly shaped right posterior temporal/parietal/occipital hematoma with significant right to left midline shift and compression of the right lateral ventricle. The decision was made to immediately take her to the operating room for surgical evacuation. Immediately prior to surgery, $r F$ VIIa was administered at a dosage of $40 \mu \mathrm{g} / \mathrm{kg}$. The hematoma was removed through a right parietal/occipital craniotomy, the surgical time was 60 minutes, and minimal bleeding was encountered during surgery. Post-op CT imaging studies showed virtual resolution of the hematoma. The 17 hour postoperative image (center) shows a small amount of residual clot and considerable improvement in midline shift. The 48 hour post-operative imaging study (right) demonstrates a small amount of increased clot in the resection cavity. Clinically, other than a left superior quadrantanopsia, she made a very good recovery and at follow-up was living independently at home.

Using the ICH Score to provide an estimate of expected mortality, it was predicted that six $(40 \%)$ deaths would occur, compared to the observed two (13\%). Based on the ICH-GS, over $70 \%$ mortality would be expected, and less than $18 \%$ of patients should have achieved a good functional outcome, compared to $73 \%$ observed in this study.

\section{DISCUSSION}

Surgical treatment of ICH remains controversial, with the majority of published studies demonstrating no overall benefit for surgery. ${ }^{21-23}$ Two studies have suggested a high post-

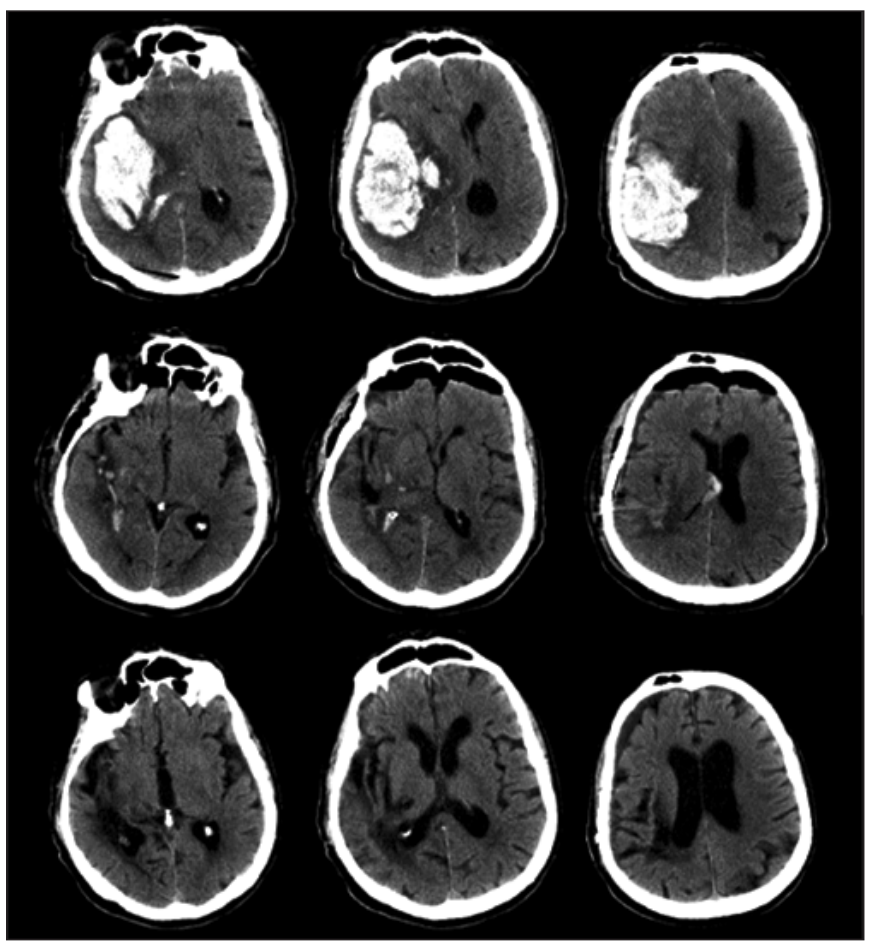

Figure 3: Pre-operative, 15 hour and 42 day post-operative CT images obtained from a 77-year-old man who presented with left hemiplegia and a rapidly decreasing level of consciousness. The pre-operative images (top row) demonstrate a large right temporal/parietal/occipital clot with a calculated volume of $164 \mathrm{ml}$ associated with considerable right to left brain shift. The 15 hour post-operative images (middle row) showed virtual resolution of the clot, and considerable improvement in the degree of brain shift. The 42-day post-operative scan (bottom row) showed right temporal/parietal residual brain injury consistent with the clot location. Clinically, the patient remained severely disabled and died at four months post-op from bowel obstruction with sepsis.

operative residual/rebleed rate as a contributing variable for poor outcome. ${ }^{15.24}$ Post-operative residual/recurrent hematoma volume was not measured in the STICH trial and, therefore, it is not possible to determine from STICH data if a subgroup exists with excellent post-operative hemostasis and superior outcome compared to medically treated patients.

This patient group, a highly selected convenience sample, may illustrate a potential new paradigm for the hyperacute treatment of spontaneous ICH. Compared to predicted, an apparent reduction in mortality and improved outcome were observed. The majority of patients $(70 \%)$ presented with large supratentorial hemorrhage together with a decreased level of consciousness. They were all considered appropriate surgical candidates. Lobar hemorrhage has a more favourable outcome than deep hemispheric or posterior-fossa hemorrhage. This would perhaps bias the present data towards a more favourable outcome compared to published series, such as STICH. ${ }^{20}$ In contrast, the large ICH volumes observed in this population should have resulted in a high rate of poor outcome or death. Existing protocols for high priority surgical intervention allowed 


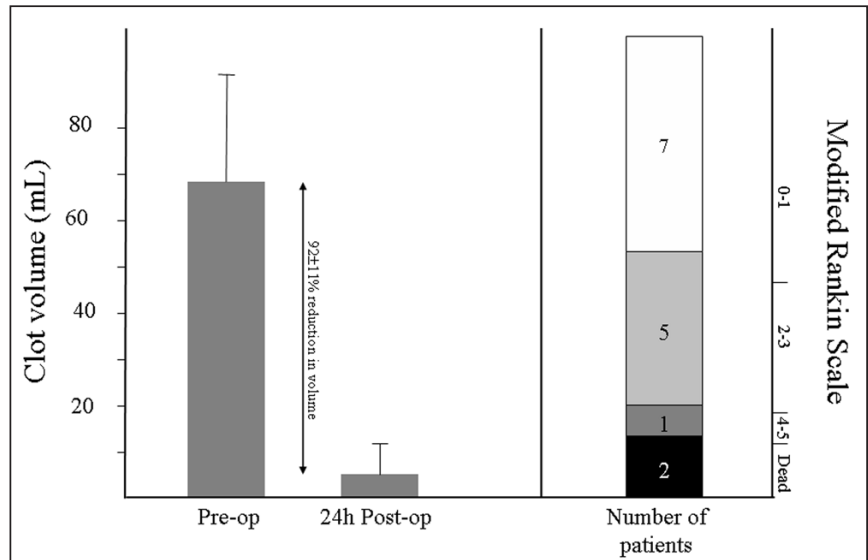

Figure 4: Clot volume and outcome for all patients.

the patients to be taken immediately to the OR for clot evacuation, permitting fast treatment times.

Published data have demonstrated that hematoma volume is a critical determinant of clinical outcome.$^{28}$ Post-operatively, a $97 \%$ reduction in hematoma volume was observed. The worst result was a $60 \%$ reduction in hemorrhage volume, due to either incomplete surgical evacuation or clot re-accumulation which could perhaps be distinguished by an intraoperative or immediate post-operative CT scan. For the majority, intraoperative hemostasis was readily achieved with bipolar coagulation, perhaps related to the effect of rFVIIa as many of the vessels within or adjacent to the clot cavity would have been pathologically abnormal and under normal circumstances, difficult to coagulate. It may be concluded that despite a half life of only 2.3 hours, ${ }^{33}$ a single dose of rFVIIa may be sufficient to obtain hemostasis in the acute surgical setting. Surgery injures the endothelium, potentially augmenting the known hemostatic mechanism associated with rFVIIa. The primary effects of rFVIIa occur locally at sites of endothelial disruption and vascular injury, where it binds to fibrin and activated platelets initiating and amplifying thrombin generation. ${ }^{34}$

This patient sample also reached an exceptional recovery given the initial hematoma size, and the pre-operative ICH and ICH-GS scores. Investigators have found that an ICH volume $>60 \mathrm{ml}$ is associated with $84-91 \% 30$-day mortality. ${ }^{28,35}$ It has also been suggested that an ICH volume of $>80 \mathrm{ml}$ is always fatal, regardless of therapy, ${ }^{35}$ although natural history studies of ICH are possibly confounded by "Do not resuscitate" orders. ${ }^{6}$ Other variables that have been shown to predict outcome include: age, GCS at presentation, intraventricular extension, and hematoma location. The ICH Grading Scale differs from the ICH score by different selection of cut-off values and point assignments. ${ }^{32}$

In the first three hours, a third of patients will show hemorrhage expansion with the proportion decreasing as the time from symptom onset increases. ${ }^{26,36,37}$ Recent observational data has suggested that patients who show contrast extravasation within the hemorrhage are the ones most likely to show expansion. ${ }^{38,39}$ Such patients may be ideal candidates for hemostatic treatment and acute surgical intervention.

These observations and this paradigm are worthy of further study. A prospective, multicentre study with appropriate controls is needed in order to confirm and expand upon the observations. To determine residual versus recurrent hemorrhage, it may be necessary to include intraoperative or immediate post-operative CT imaging. Other variables, such as blood-pressure control, that may potentially impact outcome, will need to be considered. Future studies should also include pathology studies in order to assess whether a difference exists among subgroups of patients with amyloid angiopathy or hypertension.

\section{ACKNOWLEDGEMENTS AND FUNDING}

Supported by a studentship to Christina Sutherland from Novo Nordisk, Canada.

\section{REFERENCES}

1. Intiso D, Stampatore P, Zarrelli MM, Guerra GL, Arpaia G, Simone $\mathrm{P}$, et al. Incidence of first-ever ischemic and hemorrhagic stroke in a well-defined community of southern Italy, 1993-1995. Eur J Neurol. 2003;10:559-65.

2. Qureshi AI, Tuhrim S, Broderick JP, Batjer HH, Hondo H, Hanley DF. Spontaneous intracerebral hemorrhage. N Engl J Med. 2001; 344:1450-60.

3. Anderson CS, Chakera TMH, Stewart-Wynne EG, Jamrozik KD. Spectrum of primary intracerebral hemorrhage in Perth, Western Australia, 1989-90: incidence and outcome. J Neurol Neurosurg Psychiatry. 1994;57:936-40.

4. Counsell C, Boonyakarnkul S, Dennis M, Sandercock P, Bamford J, Burn $J$, et al. Primary intracerebral hemorrhage in the Oxfordshire community stroke program. Cerebrovasc Dis. 1995; 5:26-34.

5. Daverat PD, Castel JP, Dartingues JF, Orgogozo JM. Death and functional outcome after spontaneous intracerebral hemorrhage: a prospective study of 166 cases using multivariate analysis. Stroke. 1990;22:1-6.

6. Indredavik B, Bakke F, Solberg R, Rokseth R, Haaheim LL, Holme I. Benefit of a stroke unit: a randomized controlled trial. Stroke. 1991;22:1026-31.

7. Indredavik B, Bakke F, Slørdahl SA, Rokseth R, Håheim LL. Stroke unit treatment improves long-term quality of life: a randomized controlled trial. Stroke. 1998;29:895-9.

8. Rønning OM, Guldvog B. Stroke unit versus general medical wards, II: neurological deficits and activities of daily living: a quasi-randomized controlled trial. Stroke. 1998;29:586-90.

9. Fernandes HM, Siddique S, Banister K, Chambers I, Wooldridge T, Gregson B, et al. Continuous monitoring of ICP and CPP following ICH and its relationship to clinical, radiological and surgical parameters. Acta Neurochir Suppl. 2000;76:463-6.

10. Power C, Henry S, Del Bigio MR, Larsen PH, Corbett D, Imai Y, et al. Intracerebral hemorrhage induces macrophage activation and matrix metalloproteinases. Ann Neurol. 2003;53:731-42.

11. Siddique MS, Fernandes HM, Arene NU, Wooldridge TD, Fenwick $\mathrm{JD}$, Mendelow AD. Changes in cerebral blood flow as measured by HMPAO SPECT in patients following spontaneous intracerebral hemorrhage. Acta Neurochir Suppl. 2000;76:517-20.

12. McKissock W, Richardson A, Taylor J. Primary intracerebral hemorrhage: a controlled trial of surgical and conservative treatment in 180 unselected cases. Lancet. 1961;278:221-6.

13. Auer LM, Deinsberger W, Niederkorn K, Gell G, Kleinert R, Schneider G, et al. Endoscopic surgery versus medical treatment for spontaneous intracerebral hematoma: a randomized study. J Neurosurg. 1989;70:530-5.

14. Juvela S, Heiskanen O, Poranen A, Valtonen S, Kuurne T, Kaste M, et al. The treatment of spontaneous intracerebral hemorrhage: a prospective randomized trial of surgical and conservative treatment. J Neurosurg. 1989;70:755-8. 
15. Batjer HH, Reisch JS, Allen BC, Plaizier LJ, Su CJ. Failure of surgery to improve outcome in hypertensive putaminal hemorrhage: a prospective randomized trial. Arch Neurol. 1990; 47:1103-6.

16. Chen X, Yang H, Czherig Z. A prospective randomized trial of surgical and conservative treatment of hypertensive intracranial haemorrhage. Acta Acad Med Shanghai. 1992;19:237-40.

17. Morgenstern LB, Frankowski RF, Shedden P, Pasteur W, Grotta JC. Surgical treatment for intracerebral hemorrhage (STICH): a single-center, randomized clinical trial. Neurology. 1998; 51:1359-63.

18. Zuccarello M, Brott T, Derex L, Kothari R, Sauerbeck L, Tew J, et al. Early surgical treatment for supratentorial intracerebral hemorrhage: a randomized feasibility study. Stroke. 1999;30: $1833-9$.

19. Teernstra OP, Evers SM, Lodder J, Leffers P, Franke CL, Blaauw G. Stereotactic treatment of intracerebral hematoma by means of a plasminogen activator: a multicenter randomized controlled trial (SICHPA). Stroke. 2003;34:968-74.

20. Mendelow AD, Gregson BA, Fernandes HM, Murray GD, Teasdale GM, Hope DT, et al. Early surgery versus initial conservative treatment in patients with spontaneous supratentorial intracerebral hematomas in the International Surgical Trial in Intracerebral Hemorrhage (STICH): a randomised trial. Lancet. 2005;365:387-97.

21. Hankey GJ, Hon C. Surgery for primary intracerebral hemorrhage: is it safe and effective? Stroke. 1997;28:2126-32.

22. Fernandes HM, Gregson B, Siddique S, Mendelow AD. Surgery in intracerebral hemorrhage: the uncertainty continues. Stroke. 2000;31:2511-6

23. Mendelow AD, Unterberg A. Surgical treatment of intracerebral hemorrhage. Curr Opin Crit Care. 2007;13:169-74.

24. Morgenstern LB, Demchuk AM, Kim DH, Frankowski RF, Grotta JC. Rebleeding leads to poor outcome in ultra-early craniotomy for intracerebral hemorrhage. Neurology. 2001;56:1294-9.

25. Auer RN, Sutherland GR. Primary intracerebral hemorrhage: pathophysiology. Can J Neurol Sci. 2005;Suppl 2:S3-S12.

26. Brott T, Broderick J, Kothari R, Barsan W, Tomsick T, Sauerbeck L, et al. Early hemorrhage growth in patients with intracerebral hemorrhage. Stroke. 1996;28:1-5.

27. Davis SM, Broderick J, Hennerici M, Brun NC, Diringer MN, Mayer SA, et al. Hematoma growth is a determinant of mortality and poor outcome after intracerebral hemorrhage. Neurology. 2006;66:1175-81.
28. Broderick JP, Brott T, Duldner JE, Tomsick T, Huster G. Volume of intracerebral hemorrhage: a powerful and easy to use predictor of 30-day mortality. Stroke. 1993;24:987-93.

29. Mayer SA, Brun NC, Begtrup K, Broderick J, Davis S, Diringer $\mathrm{MN}$, et al. Recombinant activated factor VII for acute intracerebral hemorrhage. N Engl J Med. 2005;352:777-85.

30. Mayer SA, Brun NC, Begtrup K, Broderick JP, Davis SM, Diringer $\mathrm{MN}$, et al. Randomized, placebo-controlled, double-blind phase III study to assess rFVIIa efficacy in acute intracerebral hemorrhage: the fast trial (abstract). Cerebrovasc Dis. 2007; 23 Suppl 2:10.

31. Kothari RU, Brott T, Broderick JP, Barsan WG, Sauerbeck LR, Zuccarello $\mathrm{M}$, et al. The ABCs of measuring intracerebral hemorrhage volumes. Stroke. 1996;27:1304-5.

32. Ruiz-Sandoval JL, Chiquete E, Romero-Vargas S, Padilla-Martínez JJ, González Cornejo S. Grading scale for prediction of outcome in primary intracerebral hemorrhages. Stroke. 2007;38:1641-4.

33. Lindley CM, Sawyer WT, Macik BG, Lusher J, Harrison JF, BairdCox $\mathrm{K}$, et al. Pharmacokinetics and pharmacodynamics of recombinant factor VIIa. Clin Pharmacol Ther. 1994;55:638-48.

34. Monroe DM, Hoffman M, Oliver JA, Roberts HR. Platelet activity of high-dose factor VIIa is independent of tissue factor. BJH. 1997;99:542-7.

35. Rådberg JA, Olsson JE, Rådberg CT. Prognostic parameters in spontaneous intracerebral hematomas with special reference to anticoagulant treatment. Stroke. 1991;22:571-6.

36. Fujii Y, Tanaka R, Takeuchi S, Koike T, Minakawa T, Sasaki O. Hematoma enlargement in spontaneous intracerebral hemorrhage. J Neurosurg. 1994;80:51-7.

37. Kazui S, Naritomi H, Yamamoto H, Sawada T, Yamaguchi T. Enlargement of spontaneous intracerebral hemorrhage: incidence and time course. Stroke. 1996;27:1783-7.

38. Becker KJ, Baxter AB, Bybee HM, Tirschwell DL, Abouelsaad T, Cohen WA. Extravasation of radiographic contrast is an independent predictor of death in primary intracerebral hemorrhage. Stroke. 1999;30:2025-32.

39. Wada R, Aviv RI, Fox AJ, Sahlas DJ, Gladstone DJ, Tomilson G, et al. CT angiography "spot sign" predicts hematoma expansion in acute intracerebral hemorrhage. Stroke. 2007;38:1257-62. 